graphic Durchmusterung.' "' This revision was chiefly an examination of all cases in which stars found in other catalogues are missing from the C.P.D. Sometimes they were hidden by photographic defects; sometimes they were variable or had large proper motion; in a great many cases they were red, and photographically faint. Hence attention was concentrated upon a particular class of stars, near the limit of the C.P.D., which had escaped registration owing to some abnormality, generally redness. This specially selected material has been further specialised, for at the top of the list we read:-Very fer stars of a lighter shade than deep yellow have been recorded because of their frequency. And this is the material from which Prof. Pearson and Miss Gibson extract their conclusions about the stars in general.

I think that an astronomer may be allowed to express his dissent from these applications of modern statistical methods.

I should like, in conclusion, to refer briefly to the theoretical point:- Should not the correlation ratio be used in preference to the coefficient of correlation? The former expresses the degree of approximation to a smooth curve, the latter the approximation to a straight line. It wil rarely happen that the curve of regression for two absolutely correlated astronomical quantities is a straight line, and the range of the quantities is generally so large that we are concerned with much more than an elementary portion of the curve. It appears to me, therefore, that it would be better in all treatment of astronomical statistics to use the correlation ratio.

Cambridge Observatory, September 23.

\section{The Relation of Man to the Animal World.}

IN the short notice given of my "booklet" in NATURE of September 12 on the "Relation of Man to Animals," the writer seems quite to have misunderstood the object of my writing it. I am aware that an author has no right to discuss a fair criticism with a reviewer, but in the present case, when the latter says that he is at a loss to discover the object and aim of my pamphlet, I trust you will allow me to give its true explanation to your readers.

I may state in a few words that if we read the report of the Vivisection Committee which has been lately sitting, we shall see that there are witnesses who confess their ignorance of the many kinds of cruelty being inflicted on animals in their very midst. This ignorance has always been considered a very important point with the advocates of experimentation as showing that the antivivisectionists shut their eyes to everything connected with the use of animals except that which is for the attainment of knowledge. This knowledge some of their leading advocates declare is no value.

When I was chosen by my college to give an address on the subject before the Church Congress, I made the present position of the animal world my basis of argument for experimentation. This feature of the question is considered most important at the present time, and therefore I have very willingly re-published and expanded it in my pamphlet. This is my sole object of writing it. It would be quite out of place to give my own opinion as to our treatment of animals generally; in fact, it would be of no value considering the difference of opinion on the subject, and especially at the present time, when vegetarianism seems largely increasing.

Hampstead, September 27 .

Samuel Wilks.

Meteoric Shower, from near $\beta$ Aurigæ.

ON September 27 at $9 \mathrm{~h}$. $54 \mathrm{~m}$. I saw a very swift meteor of about $x^{\frac{1}{2}}$ mag. shooting through Cygnus, and leaving a streak of about $10^{\circ}$ near $\alpha$ and $\gamma$ Cygni. The sky was clouding over at the time, and a portion of the luminous course of the meteor must have been hidden, but the observed path was from $306 \frac{1}{4}^{\circ}+45^{\circ}$ to $299^{\circ}+32 \frac{1}{2}^{\circ}$.

The line of flight traced far backwards carries us to the point $88^{\circ}+43^{\circ}$, and this, I believe, formed the radiant position of the object. There are showers from near $\beta$ Aurigæ in August, September, and October, and later months also supply indications of activity in the same centre. This particular system of Aurigids appears to be unusually rich from about September 21 to 27 . On 1879 September 2 I I recorded eight meteors from a radiant at $87^{\circ}+43^{\circ}$, and on 1878 September 25 the radiant near $\beta$ Aurigæ was re-determined from five meteors. The members of this stream are exceedingly swift, and they usually leave streaks, their appearance being very similar to that of the Leonids.

Bishopston, Bristol, September 28.

\section{A New Stratigraphical Fact in the Thames Basin.}

IT will interest geologists to learn of the occurrence in this neighbourhood, below the Tertiary plateau gravels, of a bed (not a boulder) of marly, lignitiferous, glauconitiferous limestone, full of fossils, about the Upper Eocene or Oligocene age, of which there can scarcely be a doubt. Fuller particulars are reserved for a later communication either to Nature or the Geological. Magazine, when the fossils have been exactly identified and the investigation completed.

This is, I believe, the first definite record in the Thames basin of pre-Miocene strata younger than the Upper Bagshot Sands.

Bishop's Stortford, September 25.

A. Irving.

\section{Bees' Stings and Rheumatism.}

It appears to be a familiar and widespread belief in many countries that the stings of bees act both protectively and as a cure for " rheumatism." I have recently been able to collect some definite evidence in support of the belief in question.

This is of interest and importance, not only on general grounds, but also on account of the connection which I believe to exist between rheumatic fever and an abnormal production of formic acid (the acid of bee poison) in the human body (British Medical Journal, September 19, 1903, and May 25, 1907)

May I, therefore, be permitted to request any of your readers who possess information on the subject, and are willing to assist the present inquiry, to favour me with answers to the following questions?-

(I) Are you acquainted with the belief that bees' stings cure and prevent rheumatism?

(2) Do you know of any case in which rheumatism is believed to have been cured by this means?

(3) Do you know of any person who suffers from rheumatism although frequently exposed to the stings of bees? $\quad$ E. W. AINLEY WALKER.

University College, Oxford, September 27.

\section{The Country Child in Education.}

IN your interesting résumé of the educational meetings at the British Association in Narure of September I2 (p. 505) one could not help being struck by the absence of any allusion, near or distant, to the country child.

I suppose it is correct to say that, physically, country children are, or will be, the backbone of the nation. If half as much were done educationally for them as is lavished on the town-and particularly the London-child, they would speedily become the nation's brain.

Manual training in all its branches, cookery lessons, swimming baths-what effect would these not have on our slow but sturdy village youngsters? With them naturestudy is coming along - but even gardening lessons on scientific principles are all too rare.

Our school buildings and furniture in country districts slowly improve, but our playgrounds are still mostly loose beach, utterly useless for physical exercises or organised games.

It is time for enlightened educationists to urge the needs and claims of the country child.

H. J. GLOVER.

Council School, Westham, Sussex, September 18.

[We hope this matter will not be lost sight of in arranging the agenda for next year's meeting of the Educational Science Section of the British Association.-ED. Nature.] 